\title{
The Wheel Keeps Turning
}

Each day I hope to contribute to making that which I can influence a little better than it was yesterday. The Journal of Sport Rehabilitation is better today than when I started. This improvement was the work of a team. It includes the past editors who created and nurtured a journal focused on rehabilitation when most journals were tied only to professional organizations. It includes the great and loyal service accomplished by many and includes associate editors, editorial assistants, managing editors, and reviewers. In fact, manuscript reviewers are the most valuable players and unsung heroes of the publication process. Without them, there would be no peer review. I am grateful to all that I had the chance to work with and learn from. The list is too long to thank everyone individually, one just has to look at the masthead to see the exceptional scholars and researchers, current and former students, and colleagues who have lent expertise to make the journal better and whom have touched my life. I am especially indebted to the collaboration and expertise of Kellie Bliven and Julia Glahn. It is important to note the effort that has been provided by the institutions that granted us the opportunity to participate. This is especially true of the University of Kentucky and AT Still University.

The wheel is turning and you can't slow down,

You can't let go and you can't hold on,

You can't go back and you can't stand still

- Robert Hunter
The wheels certainly keep turning, and it is no time to slow down. The journal is flourishing, and I am proud to have been a part of its growth. My goals were to secure Index Medicus, increase visibility, improve the international presence, increase papers that focused on rehabilitation, and promote the interprofessional and interdisciplinary nature of the journal. As I reflect on the last 12 years, I cannot go back, and I have no plans to stand still. I hope that I was able to convey the importance of fostering and providing opportunities for others to succeed. I hope that I provided a process where authors received fair and substantive reviews and where many were able to advance their scholarly agenda. While much of the work is done behind a computer screen and via a keyboard, I hope that I was able to provide the power of a smile, a kind word, a listening ear, or honest compliment to improve the quality of a manuscript and support those willing to share original research with the Journal of Sport Rehabilitation.

Too often we underestimate the power of a touch, a smile, a kind word, a listening ear, and honest compliment, or the smallest act of caring, all of which have the potential to turn a life around.

— Leo Buscaglia

Yours in health, Carl G. Mattacola, Editor-in-Chief 